\title{
Abordagens psicolinguísticas na pesquisa em leitura e escrita: instrumentos e procedimentos
}

\author{
Psycholinguistics approach to the reading and writing research: instruments and procedures
}

\author{
Ana Cláudia de Souza \\ Universidade Federal de Santa Catarina - Florianópolis - Santa Catarina - Brasil \\ Otilia Lizete de Oliveira Martins Heinig \\ Universidade Regional de Blumenau - Blumenau - Santa Catarina - Brasil
}

\begin{abstract}
Resumo: Neste artigo, apresentam-se os instrumentos e procedimentos de pesquisa na investigação de processos e produtos de leitura e escrita, elaborados e aplicados nos estudos de doutorado de autoria de Heinig (2003) e Souza (2004), na subárea de Psicolinguística, área de concentração Aquisição e Processamento da Linguagem, do Programa de Pós-Graduação em Linguística da Universidade Federal de Santa Catarina. A pesquisa de Heinig, conduzida por meio de uma intervenção colaborativa de 25 estudantes da antiga quarta série do Ensino Fundamental, se dedicou ao ensino e à aprendizagem da codificação como um processo significativo de correspondência fonológico-grafêmica permeado por memória lexical ortográfica, analisando o contexto competitivo no qual estão os itens homófonos não homógrafos. Souza, por sua vez, investigou, com 40 estudantes de Letras, processos de leitura de texto acadêmico-científico deliberadamente construído sobre metáforas pedagógicas, focalizando as diferenças cognitivas individuais de capacidade da memória de trabalho.
\end{abstract}

Palavras-chave: Método de pesquisa; Psicolinguística; Leitura; Escrita

\begin{abstract}
This paper presents the research instruments and procedures of the doctoral investigations of Heinig (2003) and Souza (2004) on the reading and writing processes and products, developed and applied in the Language Acquisition and Processing area of concentration of Psycolinguistics into the Linguistics Graduate School of Federal University of Santa Catarina. Heinig`s research was a collaborative intervention with 25 students from de $4^{\text {th }}$ grade of Elementary School. Its aim was to investigate teaching and learning encoding as a significant process of fonological-grafemic correspondence permeated by the lexicalorthographic memory. In this case, the competitive contexts where there are homographs items that are not homophones are analyzed. Souza's investigation was carried out with 40 undergraduate students from the Language Course. It aimed at studying the reading process of academic-scientific texts which were deliberated written through pedagogical metaphors. Thus, it took into consideration cognitive individual differences in terms of working memory capacity.
\end{abstract}

Keywords: Research method; Psycholinguistics; Reading; Writing

\section{Descrição das pesquisas}

Por meio deste artigo, objetiva-se apresentar, fundamentar e discutir aspectos relativos aos instrumentos e procedimentos dos métodos de pesquisa de doutorado de Heinig (2003) e Souza (2004), elaborados e implementados na subárea de Psicolinguística, do Programa de Pós-Graduação em Linguística da UFSC. Inicialmente descrevem-se estas pesquisas, que se caracterizam por serem quanti-qualitativas, naquilo que diz respeito às suas naturezas, propósitos, temas, hipóteses e público-alvo.
Heinig (2003) desenvolveu seu doutoramento sob a orientação da Professora Leonor Scliar-Cabral, tendo conduzido a pesquisa, de caráter colaborativo e intervencionista, no campo da pesquisa-ação experimental, com foco na emergência e no desenvolvimento inicial da competência escrita, intitulada "É que a gente não sabe o significado": homófonos não homógrafos. Por se tratar de investigação dedicada aos processos envolvidos na produção de textos com vistas a compreender como acontece o ensino e a aprendizagem da codificação, o estudo de Heinig se situa no âmbito da Psicolinguística 
Aplicada. Interessa a esta pesquisa principalmente a escolha dos grafemas depois de selecionada a inserção do item lexical na frase, momento em que quem escreve deve selecionar, entre os grafemas que codificam a realização de determinados fonemas, aquele que é adequado ao contexto. Considerando que, no caso de homófonos não homógrafos, como conserto/concerto, cozer/coser, seção/ sessão, o contexto é competitivo, mais de uma seleção de grafema pode parecer adequada; por isso, a escolha, permeada por traços da variedade sociolinguística daquele que escreve, depende do significado atribuído ao item lexical.

Os objetivos desta investigação foram identificar e analisar as dificuldades presentes em alunos da antiga quarta série do Ensino Fundamental, nas situações que requerem grafia e explicação dos homófonos não homógrafos da mesma classe gramatical; investigar o conhecimento dos professores desta etapa da escolarização sobre o ensino e a aprendizagem de tais homófonos e, ainda, propor intervenções metodológicas para o ensino de homófonos não homógrafos da mesma classe sintática.

Participaram da intervenção colaborativa 25 estudantes do Colégio São Luiz, situado em Brusque/ SC. Totalizaram quatro as etapas de coleta de dados e intervenção, cada uma delas detendo-se, respectivamente, nas questões, que serão exploradas ao longo deste artigo, especialmente no que diz respeito aos instrumentos e aos procedimentos metodológicos. O primeiro momento se dedicou ao estabelecimento do perfil dos participantes, ao desenvolvimento dos jogos sobre homônimos que serviram como material didático na intervenção colaborativa e à pré-testagem relativa ao conhecimento dos sujeitos quanto ao tema investigado. Tendo selecionado as turmas e definido os grupos experimento (GE) e controle (GC), no segundo momento aplicaram-se dois instrumentos de coleta de dados com vistas a estabelecer o perfil do grupo no qual seria desenvolvida a intervenção, a saber: bateria de testes de recepção e produção da língua portuguesa, de Scliar-Cabral (2003), e questionário psicolinguístico e socioeconômico dos estudantes. A terceira etapa foi aquela em que ocorreu a intervenção colaborativa, mantendo o mesmo conteúdo nos grupos experimento e controle, com diferença de intervenção metodológica, tendo-se utilizado, com o GE, os jogos elaborados na primeira etapa. A quarta etapa se voltou à aplicação do pós-teste (idêntico ao pré-teste), a fim de verificar diferenças no desempenho do GE e do GC, intra e intergrupo, quanto à grafia correta dos homófonos não homógrafos e à capacidade de justificar as escolhas realizadas.

A seu turno, a pesquisa de Souza (2004), intitulada Leitura, metáfora e memória de trabalho: três eixos imbricados foi desenvolvida sob a orientação de Loni Grimm-Cabral e coorientação de Cassio Rodrigues, voltando-se à investigação da relação entre a capacidade da memória de trabalho e a leitura (tanto em termos de processo quanto de produto da compreensão) de textos escritos acadêmico-científicos, marcados pelo emprego deliberado de metáforas pedagógicas, na exposição de sua ideia central. Pedagógicas, segundo van Besien (1989), são as metáforas deliberadamente produzidas com o intuito de esclarecer conceitos ou teorias cujo acesso direto poderia ser impossibilitado, dadas as abstrações implicadas. O intuito da pesquisa foi investigar a compreensão, por meio da descrição das estratégias empregadas pelos leitores na produção do sentido da metáfora deliberada, da sua relação com a competência em leitura e da capacidade da memória de trabalho.

Os participantes desta pesquisa foram 40 estudantes do Curso de Letras da Universidade do Extremo Sul Catarinense, indivíduos em processo de formação inicial em curso de licenciatura que habilita para o ensino da leitura.

A investigação foi conduzida a partir da formulação da hipótese geral de pesquisa segundo a qual o emprego deliberado de expressões metafóricas novas, na elaboração de textos escritos, exige grande empenho cognitivo do leitor no sentido de (re)construir os jogos sugeridos pelo autor, tendo em vista a centralidade e o caráter não convencional das metáforas pedagógicas utilizadas na esfera social acadêmico-científica. Além disso, foi desenvolvida pesquisa descritiva e exploratória objetivando identificar as semelhanças de comportamento dos participantes diante do texto, as estratégias de leitura por eles empregadas e a relação dessas estratégias com a competência em leitura geral e específica à metáfora e com capacidade da memória de trabalho em leitura e em operações matemáticas.

Para conduzir o estudo exploratório e testar a hipótese geral de pesquisa e seus desdobramentos, foram elaborados e aplicados quatro instrumentos de coleta de dados, que serão descritos e discutidos neste artigo tanto em termos de fundamentos quanto de procedimentos de aplicação e análise, a saber: 1) Teste de capacidade da memória de trabalho em leitura - reading span test (DANEMAN; CARPENTER, 1980; TURNER; ENGLE, 1989; TOMITCH, 2003; TORRES, 2003), 2) Teste de capacidade da memória de trabalho em operações matemáticas - operation-word span test (TURNER; ENGLE, 1989; CANTOR; ENGLE, 1993; FORTKAMP, 2000), 3) Técnica dos protocolos verbais (ERICSSON; SIMON, 1980; 1993; SOUZA; RODRIGUES, 2008) e 4) Teste de competência em leitura (BRASIL, 2001; ORGANISATION FOR ECONOMIC CO-OPERATION AND DEVELOPMENT, 2003). 
Além dos quatro instrumentos de coleta centrais à pesquisa, foi aplicada uma bateria de três provas de raciocínio, padronizada para a população brasileira, com o propósito de dar suporte aos testes de capacidade de memória, não sendo, porém, considerados seus resultados na discussão das perguntas e hipóteses de pesquisa. Esta bateria de provas de raciocínio, de autoria de Primi e Almeida (2000), oferece estimativas do funcionamento cognitivo geral e das habilidades do indivíduo em áreas específicas, conforme os testes selecionados: raciocínio abstrato, verbal e numérico.

\section{Instrumentos e procedimentos da pesquisa de Heinig (2003)}

Nesta seção, intenciona-se descrever a metodologia desenvolvida para a pesquisa e refletir sobre seu uso e implicações, pois o desenho metodológico permite estabelecer relações entre dados, análises e resultados.

Esta pesquisa foi caracterizada como ação, embora também se tenha utilizado o método experimental, a fim de se poder estabelecer a comparação entre dois grupos do mesmo universo. Haguette (2003, p. 98), ao distinguir os tipos de pesquisa-ação, a partir dos estudos de Lewin, apresenta a pesquisa-ação experimental: "que exige um estudo controlado da eficiência relativa de técnicas diferentes em situações sociais praticamente idênticas".

A pesquisa-ação (BARBIER, 2002; HAGUETTE, 2003; THIOLLENT, 2009; ANDRÉ, 2008), termo cunhado por Kurt Lewin, originou-se na psicologia social na década de quarenta. A posteriori, foi sofrendo alterações e, atualmente, aparece sob a forma de investigação colaborativa ou cooperativa, que defende um trabalho feito em conjunto e a colaboração progressiva entre pesquisador e pesquisado. Levando em conta os pontos de vista das várias correntes que estudam esse tipo de pesquisa, é possível defini-la como aquela que "envolve sempre um plano de ação, plano esse que se baseia em objetivos, em um processo de acompanhamento e no relato concomitante desse processo [...] Muitas vezes esse tipo de pesquisa recebe o nome de intervenção" (ANDRÉ, 2008, p. 33).

Por ser, nesta tese, o objeto de interesse a sala de aula e o trabalho do professor, optou-se pela pesquisaação, pois se apoia em uma abordagem etnográfica, a qual visa estimular o pesquisador prático, envolvendo cada vez mais o professor na pesquisa. Segundo André (op. cit., p. 120), nesse caso, as formas podem ser diversificadas, tendo, de um lado, um pesquisador responsável pelo planejamento e direção do estudo e o professor atuando como colaborador e, de outro, o professor centrando a pesquisa na sua própria prática. No caso da pesquisa aqui apresentada, a primeira forma foi a escolhida, e o professor foi um colaborador, que ajudou a fazer registro de campo, a fornecer material e a discutir os resultados com o pesquisador. Essa tendência, que visa aproximar sujeito e objeto, por conseguinte aproxima etnografia e investigação-ação. Dessa forma, surgem novos caminhos, nos quais há a associação das duas formas de pesquisa ou o surgimento de formas mistas, o que será benéfico para a área da educação.

Além disso, é preciso que haja integração entre ensino e pesquisa na universidade, uma vez que, de acordo com Santos (2002, p. 23), isso representa um grande problema a ser superado; assim, a integração "só será possível quando o ensino for colocado como prioridade ao lado da pesquisa, dispensando-lhe o interesse e os cuidados conferidos a esta última". Corroborando essa ideia, Lisita, Rosa e Lipovetsky (2002) enfatizam a necessidade de uma cooperação maior entre os pesquisadores da universidade e os professores - investigadores de sua prática pedagógica - que se encontram em sala de aula, para que haja contribuição efetiva entre os dois lados com o propósito de que novos conhecimentos sobre o ensino, a aprendizagem e a aprendizagem para ensinar possam ser construídos.

Essa perspectiva metodológica conduz à seleção de instrumentos de coleta de dados que consigam abarcar os aspectos psicolinguísticos e educacionais, a fim de que essa soma permita alcançar a proposta geral da tese, que foi investigar o ensino e a aprendizagem de homófonos não homógrafos de mesma classe gramatical. Embora se tenha optado por quatro etapas, cada uma com um objetivo específico, tal como descrito nesta seção, todas colaboraram para alcançar o objetivo geral aqui proposto.

A primeira etapa visou conhecer os participantes da pesquisa, estabelecendo o perfil dos sujeitos. A opção por pesquisa experimental exige seleção criteriosa de sujeitos, o que permite a análise comparativa entre GE e GC, considerando, neste caso, as variáveis: mesma professora, metodologia de ensino, idade, turma, rendimento escolar. Quanto ao último item, para traçar um perfil, foi realizada a média das notas alcançadas, no primeiro bimestre, pelos alunos das duas turmas. Já o viés etnográfico demanda o conhecimento do campo de atuação do pesquisador e, por isso, passou-se a ter um contato mais estreito com a comunidade escolar: direção, reunião com os professores, observação das aulas bem como a análise do material didático de Língua Portuguesa do qual se extraiu o corpus de homônimos que serviu para a construção do pré e pós-testes, do banco de palavras de alguns jogos e das atividades realizadas na terceira etapa. No que tange ao caráter de pesquisa-ação e colaborativa, foram desenvolvidos os instrumentos de coleta de dados, os quais passaram por validação, bem como os jogos, os quais foram organizados em cartelas pela pesquisadora, 
e em CD-ROM, em parceria com o laboratório de informática da escola.

Para o levantamento do conhecimento prévio dos alunos participantes, aplicou-se um pré-teste, o qual foi elaborado com a intenção de se verificar tanto a forma como os sujeitos grafavam os homófonos não homógrafos como a construção de explicação para a grafia das palavras, o que mobiliza os conhecimentos arquivados nas memórias semântica e lexical. Depois de validado, foi aplicado no GE e no GC em iguais condições. Os cuidados com a aplicação são essenciais para organizar a intervenção colaborativa junto ao $\mathrm{GE}$, bem como para estabelecer comparações analíticas entre grupos e entre respostas produzidas antes e depois do estudo, pelos sujeitos. Quanto aos procedimentos analíticos, o pré-teste teve seus dados divididos em dois grupos: um relacionado ao número de acertos e outro às justificativas produzidas pelos sujeitos; foi verificado também o elo entre a grafia e a justificativa. Os números de acertos foram submetidos ao teste qui-quadrado, para análise da significância estatística. Esse tipo de teste trabalha com duas hipóteses e, através dele, é possível comparar dois ou mais grupos para verificar se são ou não diferentes. Além disso, os tipos de acertos e erros foram categorizados, de modo que se pudesse estabelecer um perfil dos sujeitos participantes quanto à forma como grafaram a palavra ditada. Partindo das palavras grafadas, foram levantadas seis categorias: 1) correta; 2) homófonos; 3) NILO (não internalizada no léxico ortográfico); 4) RNI (regra não internalizada) que se refere aos problemas de codificação; 5) problemas maiores (que se referem à sintaxe ou à percepção); 6) escreve como fala. Aos dados da categoria 1, levando-se em conta todas as 20 palavras ditadas, aplicou-se a estatística descritiva, que forneceu dados como média, mediana, moda, desvio padrão e número mínimo e máximo de acertos, os quais visaram complementar os resultados alcançados pelo teste qui-quadrado. Quanto às justificativas, foram organizadas em 14 categorias $^{1}$ às quais, além do tratamento qualitativo, aplicou-se o teste qui-quadrado, verificando-se a significância estatística da frequência das justificativas consideradas boas e inadequadas. Esse teste também foi aplicado nas respostas com elo pelos sujeitos, para detectar a possível diferença entre os dados do pré e do pós-teste.

\footnotetext{
Conhecimento do sentido (relação significado/grafia; atribuição do sentido a partir do contexto); conhecimento dos princípios do sistema alfabético do português do Brasil; derivação [cognato]; frequência de uso (de exposição (leitura); de escrita); conhecimento prévio da palavra (com justificativa; sem justificativa); relação som versus leitura e escrita; dúvida na grafia (explicitação da dúvida; não explicitação da dúvida); desconhecimento da palavra; não compreensão da diferença entre homófonos não homógrafos; má internalização das regras grafêmicofonológicas; ausência de explicação; estratégia de preenchimento; achismo; não sabe redigir a resposta.
}

Em paralelo, também ocorreu a observação participante. Este instrumento de coleta de dados é obtido "por meio do contato direto do pesquisador com o fenômeno observado, para recolher as ações dos atores em seu contexto natural, a partir de sua perspectiva e seus pontos de vista" (CHIZZOTTI, 2008, p. 90). A pesquisadora participou das aulas de Língua Portuguesa nas duas turmas observando como eram desenvolvidas, como o material, então adotado, era trabalhado e como os alunos participavam das atividades. Semanalmente, foram observadas onze aulas em cada turma, feito o acompanhando dos alunos em outras atividades como biblioteca e laboratório de informática, e descritos os dados no diário de campo.

As atividades aplicadas na terceira etapa tiveram sua base na análise do material didático e nas aulas observadas. Dentre o que foi produzido, serão aqui descritos os jogos desenvolvidos pela pesquisadora, os quais estão relacionados com o conhecimento avaliado no pré e pós-testes. O jogo da forca, já conhecido dos participantes, foi elaborado a partir dos homófonos não homógrafos presentes nas duas apostilas adotadas pela escola; o jogo da memória que, no CD-ROM, recebeu o nome de palavras e figuras, incluiu novos homófonos não homógrafos, a fim de os alunos criarem os pares com os já apresentados no jogo da forca; o completar frases retomou as palavras trabalhadas nos dois jogos anteriores, e o aluno deveria usar as informações presentes na frase para descobrir qual grafia escolher. Diferentemente dos anteriores, não era apresentada a confirmação de acerto da resposta, pois o objetivo era levar o aluno à discussão em torno das estratégias usadas para escolher a alternativa que completasse aquele contexto; o achando o significado retomou conhecimentos já trabalhados e acrescentou novos, visando trabalhar a elaboração de definição, que já vinha sendo desenvolvida pelos alunos no "Dicionário de homônimos"; o de pares opostos explorou o uso de prefixos que provocam a homonímia. Foram selecionados os prefixos: des-, dis-; en(m)-; in(m)-, i-; ante-, anti-; ex-; e-. Para a seleção das palavras, foram consultados o material elaborado por Scliar-Cabral (2003) e gramáticas (BECHARA, 1969, 2003; SACCONI, 1994; ROCHA LIMA, 1982; MESQUITA, 1994); o bingo de homônimos, foi usado para finalizar as atividades, tendo em vista que apresenta o maior número de palavras, as quais fazem parte dos jogos anteriores e de outros materiais consultados, em especial, o elaborado por Scliar-Cabral (2003).

A segunda etapa visou estabelecer o perfil do grupo no qual seria desenvolvida a intervenção colaborativa. Para isso foram utilizados dois instrumentos: a bateria de testes de recepção e produção da língua portuguesa, de ScliarCabral (2003), e o questionário psicossociolinguístico e 
socioeconômico, adaptado da proposta de Scliar-Cabral (2003). Com o primeiro, objetivou-se, especialmente, fazer um diagnóstico da turma, a fim de identificar problemas relacionados ao processo de alfabetização dos alunos. A análise dos dados seguiu as orientações da própria bateria, permitindo levantar os conhecimentos individuais dos participantes - pois os testes foram aplicados individualmente -, bem como traçar um perfil da turma em um levantamento quantitativo dos resultados, por teste aplicado. $\mathrm{O}$ segundo, composto por dezessete questões, visou à obtenção de dados pessoais (família, convívio, instrução e profissão dos pais, religião, residência), dados sobre a saúde, gostos e hábitos da criança, variante da língua utilizada e relação com a escola, os quais foram analisados quantitativamente.

Na terceira etapa, ocorreu a intervenção colaborativa para a qual a pesquisadora e a professora planejaram, semanalmente, as aulas tendo como referência o material didático utilizado pelos alunos. Isso permitiu que o mesmo conteúdo fosse trabalhado nos dois grupos, sendo que, no GC, seguiu-se a proposta adotada pela escola e, para $\mathrm{GE}$, além dos textos e exercícios, foram delineados os instrumentos específicos para a metodologia desenvolvida na intervenção colaborativa.

Durante o contato com a turma, foi realizada observação participante, e as aulas foram registradas em um diário de campo, além de terem sido gravadas e transcritas. Realizou-se também a aplicação das atividades planejadas para o ensino-aprendizagem dos homófonos não homógrafos, sendo a principal delas os jogos. A partir deles, foram desenvolvidas outras atividades que visavam à coleta de dados: dicionário de homônimos, ditado interativo e releitura focalizada. $\mathrm{O}$ dicionário foi construído à medida que as palavras foram surgindo durante as discussões. As intervenções foram anotadas em um caderno especial com as letras do alfabeto, sendo registradas as palavras aprendidas, sua definição e um exemplo, elaborados da forma como o aluno compreendera a palavra. O ditado interativo e a releitura focalizada aconteceram semanalmente; às vezes, os dois juntos na mesma semana; outras vezes, apenas um ou outro. A escolha recaía sobre a palavra a ser trabalhada naquele momento, de acordo com o planejamento, estando ela conectada com outros tipos de atividades como os jogos, cartazes explicativos, ilustrações, elaboração de textos explicativos tanto em pequenos grupos como individualmente.

Tendo em vista a grande produção de material nesta fase, na análise, optou-se por um recorte dos dados, para ilustrar como foram desenvolvidas as aulas, as quais foram, inicialmente, apresentadas em um quadro que sintetizou, cronologicamente, o trabalho desenvolvido, com destaque para os itens lexicais explorados e para as atividades. Na etapa destinada à discussão de cada passo desenvolvido, a análise qualitativa teve como dados a produção escrita dos sujeitos, a partir das atividades planejadas, e as falas gravadas durante as aulas, para que se pudesse compreender como foi ocorrendo a reflexão dos participantes a respeito dos homófonos não homógrafos da mesma classe gramatical.

Finalmente, aplicou-se o pós-teste, a fim de se verificar se houve ou não diferença quanto à grafia correta dos homófonos não homógrafos e à capacidade de justificar as escolhas realizadas. O teste aplicado foi o mesmo do pré-teste, assim como a análise e o tratamento estatístico. O pós-teste, quando se opta pelo método experimental, permite estabelecer a comparação entre dois grupos do mesmo universo, mas, ainda que haja um tratamento estatístico cuidadoso para a comparação dos dados antes e após a intervenção colaborativa, quando se aproxima a pesquisa-ação da experimental, é preciso considerar, além dos resultados quantitativos, o processo de aprendizagem e nele o método adotado e o planejamento executado, que se traduzem em análise qualitativa. $\mathrm{Na}$ triangulação dos dados e na aproximação das abordagens quanti-qualitativa é que podem ser atingidos os objetivos traçados para a pesquisa

Encerrando a seção, é importante destacar que o tipo de pesquisa desenvolvido possibilitou a integração entre ensino e pesquisa. Trata-se de pesquisa-ação, que se apoiou numa abordagem etnográfica, visando estimular o pesquisador prático e envolver o professor na pesquisa, pois oportunizou a circulação entre teoria e prática, fazendo não só com que o professor analisasse a sua forma de trabalho, mas também que o pesquisador revisasse suas propostas teóricas. Para o pesquisador, é uma oportunidade para compreender, na prática, como sua proposta teórica funciona, para quem se destinam seus achados teóricos, se estão corretos, se precisam de ajustes, ou seja, é a possibilidade de ir da teoria à prática e voltar à teoria, promovendo a socialização do conhecimento e a validação empírica da teoria. Sobretudo, este tipo de pesquisa ratifica a ideia de Lisita, Rosa e Lipovesty (2002), apoiada em vários autores da pesquisaação: a necessidade de uma cooperação maior entre os pesquisadores, que se encontram na universidade, e os professores, investigadores de sua prática pedagógica, que se encontram em sala de aula, para que haja contribuição efetiva entre os dois lados, a fim de que novos conhecimentos sobre o ensino, a aprendizagem e a aprendizagem para ensinar possam ser construídos.

\section{Instrumentos e procedimentos da pesquisa de Souza (2004)}

O intuito desta seção é apresentar parte do método da pesquisa de Souza (2004), focalizando os instrumentos 
e os procedimentos de coleta de dados, que foram desenvolvidos com o propósito de investigar e explorar o processo e o produto da leitura de textos acadêmicocientíficos elaborados sobre metáforas pedagógicas. Segundo van Besien (1989), tais metáforas funcionam como recursos facilitadores da explanação acerca de construtos teóricos, encorajando a memorização da informação e gerando uma melhor e mais intuitiva compreensão.

Neste estudo, de caráter correlacional, descritivo e exploratório, observaram-se os processos implicados no ato da leitura de texto acadêmico-científico, elaborado sobre bases metafóricas, colocando em evidência as diferenças cognitivas individuais, em termos de capacidade da memória de trabalho, como agentes de interferência no processamento e consequente compreensão do texto escrito.

Para conduzir a investigação, foram desenvolvidos e aplicados quatro instrumentos de coleta de dados, quais sejam: 1) Teste de capacidade da memória de trabalho em leitura - reading span test; 2) Teste de capacidade da memória de trabalho em operações matemáticas operation-word span test; 3) Técnica dos protocolos verbais; 4) Teste de competência em leitura.

As medidas de capacidade da memória de trabalho utilizadas neste estudo refletem visões diferentes acerca dos recursos de capacidade deste sistema de memória. Enquanto para Daneman e Carpenter (1980) a capacidade da memória de trabalho é relativa a uma tarefa específica, para Turner e Engle (1989) ela é de domínio geral. A literatura tem demonstrado que ambas as postulações são preditivas em relação à compreensão da linguagem (DANEMAN; MERIKLE, 1996), devido ao fato de que a tarefa requer tanto capacidade de memória de trabalho, quanto habilidade na execução da tarefa específica de compreensão da linguagem.

O teste de capacidade de memória de trabalho em leitura utilizado nesta pesquisa se baseou no modelo proposto por Daneman e Carpenter (1980) e adaptado por Turner e Engle (1989), consistindo de 60 frases não relacionadas entre si, compostas por, no mínimo, 13 e, no máximo, 17 palavras. As frases foram agrupadas, em número crescente, da seguinte maneira: 3 conjuntos de 2 frases (nível 2), 3 conjuntos de 3 frases (nível 3), 3 conjuntos de 4 frases (nível 4), 3 conjuntos de 5 frases (nível 5) e 3 conjuntos de 6 frases (nível 6).

À metodologia proposta por Turner e Engle (1989) adicionou-se um julgamento de gramaticalidade, que consistiu da análise das frases-estímulo em termos de organização das palavras. Gramaticais, nesse sentido, foram consideradas as frases cuja sequência de palavras respeitasse a gramática da língua portuguesa. Associouse a recuperação das palavras a esse julgamento com o intuito de assegurar que os participantes processassem toda a frase, pelo menos em termos sintáticos, e não apenas memorizassem as últimas palavras, o que poderia levar a uma medida de armazenamento, sem considerar o processamento da informação.

O teste de memória de trabalho em operações matemáticas, por sua vez, consistiu do processamento de informações matemáticas, em operações complexas de multiplicação ou divisão seguidas de adição ou subtração. Quanto ao armazenamento, utilizou-se um elemento verbal, substantivo de até 4 sílabas, posicionado do lado direito da operação matemática.

Exatamente como procedeu no teste de memória em leitura, Souza elaborou o teste em matemática, guardadas as especificidades de cada instrumento. Foram oferecidos aos participantes 60 estímulos visuais, em cinco níveis, envolvendo sempre divisão ou multiplicação seguida de soma ou subtração. Depois de resolver silenciosamente cada operação matemática complexa, o participante deveria julgar o resultado final como correto ou incorreto. Somente após a oferta de um conjunto de operações matemáticas, o participante recuperaria as palavras na exata forma e sequência de apresentação (FORTKAMP, 2000).

Quanto aos procedimentos de coleta, os dois testes de memória de trabalho foram aplicados individualmente a cada um dos participantes, em sessão única, utilizando o programa Power Point para a exibição dos estímulos, em tempo invariável, previamente determinado. O nível da estimativa de capacidade da memória de trabalho, nas duas tarefas, foi calculado por meio dos acertos dos participantes no julgamento da gramaticalidade ou da correção de cada operação matemática, mais a recuperação correta de todas as palavras finais de cada um dos agrupamentos, na mesma forma e sequência de apresentação dos estímulos. O nível de capacidade seria aquele em que o participante julgasse adequadamente a gramaticalidade ou o resultado final das operações e recuperasse as palavras em, pelo menos, dois dos três agrupamentos de cada nível. Atribuía-se meio ponto ao nível máximo em que o participante acertasse apenas um dos três agrupamentos.

$\mathrm{O}$ terceiro instrumento de coleta desta pesquisa foi a técnica dos protocolos verbais, que consistiu das verbalizações do sujeito acerca dos processos mentais durante a execução da tarefa (meta)cognitiva de leitura. $\mathrm{O}$ emprego da técnica pressupõe a execução simultânea de duas tarefas: a tarefa experimental (neste caso específico, a leitura) e o relato dos processos cognitivos que ocorrem durante a execução desta tarefa. Uma das importantes questões relacionadas a esta técnica é o fato de que, quando os participantes relatam, obtém-se informação acerca do processamento da informação e do funcionamento dos 
seus sistemas de memória, principalmente da memória de trabalho (ERICSSON; SIMON, 1980, 1993, 1998).

A técnica dos protocolos verbais é válida por uma série de razões, como as explicitadas por Afflerbach e Johnston (1984). Uma das vantagens é que a validade dos relatos verbais está pautada em um amplo conjunto de hipóteses, que subjazem a muitos dos outros métodos de investigação dos processos cognitivos. Além disso, sob certas circunstâncias, os dados fornecem descrições autênticas dos processos cognitivos que, sob outra perspectiva, somente poderiam ser investigados indiretamente.

Na pesquisa de Souza (2004), a técnica dos protocolos verbais foi aplicada individualmente, com dois textos acadêmico-científicos (materiais-base da pesquisa), e as falas foram gravadas, a fim de que se pudesse transcrevêlas para posterior análise. Com o emprego desta técnica, objetivou-se examinar o processo de leitura e identificar as estratégias empregadas pelos participantes com o objetivo de compreender os textos que estavam sendo lidos. Como os textos foram expostos na tela do computador, parágrafo a parágrafo, foi possível, além de acessar os dados dos protocolos verbais, mensurar os movimentos de avanço, recuo e parada que cada um dos sujeitos fez ao ler os textos-estímulo.

Foi por meio da técnica dos protocolos verbais que se identificaram as seguintes estratégias de leitura aplicadas pelos participantes: fuga do assunto, leitura em voz alta, construção do sentido, avaliação da própria compreensão e avaliação do texto. Depois de transcritos os dados, buscaram-se, por meio de uma varredura em todo o protocolo, as estratégias de leitura da metáfora pedagógica empregadas pelos participantes. Dada a espontaneidade do relato, os participantes não foram instigados a fornecer a informação desejada. Não se trabalhou, portanto, com uma unidade definida de análise, já que nem tudo o que eles relataram podia efetivamente ser considerado estratégia de leitura.

Por fim, o quarto instrumento se refere à testagem da competência em leitura, por meio do acesso ao desempenho, ou seja, ao produto do ato de ler. O instrumento de coleta de dados desenvolvido e aplicado se baseia no Programa de Avaliação Internacional de Estudantes, PISA-2000. Este sistema de avaliação se mostrou eficaz na análise do desempenho do leitor na construção do sentido (BRASIL, 2001). Por essa razão, serviu de base à elaboração do instrumento de pesquisa de tese. Contudo, há diferenças significativas entre a testagem Pisa e aquela proposta no âmbito do estudo de tese de Souza (2004). Entre elas está o fato de a testagem da competência em leitura se restringir, na tese, à leitura de texto acadêmico-científico, da área de formação dos estudantes de Letras, desenvolvido a partir de metáforas pedagógicas deliberadamente empregadas, enfatizando-se somente a situação de leitura em busca da aprendizagem, ou seja, ler para aprender.

Foram examinadas as seguintes competências no processo de compreensão do texto: 1) Identificação e recuperação da informação: procura, localização e seleção das informações textuais relevantes, explícitas ou não, em frases ou blocos maiores de texto; 2) Interpretação: integração entre a informação textual e o conhecimento prévio, fazendo inferências sempre que necessário; 3) Reflexão e avaliação: observação e análise textual objetiva, formulação de hipóteses e avaliação crítica das propriedades do texto, habilidade que requer alto grau de monitoramento cognitivo, estabelecimento de conexões, comparações, explicações ou avaliações de características de um texto.

Quanto à proficiência em leitura, o Programa PISA-2000 considera cinco níveis, que, resumidamente, partem da localização de informações mais proeminentes e concretamente explícitas num texto de assunto familiar, passam pelos processos de inferenciação e estabelecimento de relações entre o texto e experiências pessoais e chegam à compreensão de textos longos ou complexos, formulação de hipóteses e avaliação crítica de texto não-familiar ao leitor. No teste desenvolvido para a pesquisa de doutorado, avaliaram-se fundamentalmente os níveis mais elevados, visto que o objeto de leitura foram textos acadêmico-científicos, ricos em recursos metafóricos deliberados, como meio para explicitar um construto teórico/abstrato, o que exigiu dos participantes níveis elevados de proficiência. Apenas em algumas questões em que a informação poderia ser mais facilmente localizada, este nível foi mais baixo.

No que diz respeito à composição, o teste foi elaborado com um total de 16 questões em três formatos: 10 questões discursivas abertas, 4 de múltipla escolha e 2 semiabertas. Nas questões discursivas, os participantes foram solicitados a fornecer uma breve resposta a partir de uma variedade de possibilidades ou a construir uma resposta mais ampla, sem que explicitamente existissem concorrentes. Nas questões de múltipla escolha, foram oferecidas quatro alternativas, sendo que em todas as questões havia a presença de distratores, respostas parciais à questão, ou seja, respostas que partilhavam traços com a informação solicitada, sem satisfazer completamente o que fora perguntado (KIRSCH, 2001). Nas questões semiabertas, solicitou-se a identificação de elementos textuais não explícitos, sem que houvesse a necessidade de elaboração textual para responder.

O teste de competência em leitura foi o único dos instrumentos principais de coleta de dados aplicado a grupos de estudantes, que se organizaram conforme suas disponibilidades, já que se tratava de testagem silenciosa, 
em que os sujeitos se encontravam diante de teste impresso em papel e caneta. A competência em leitura foi determinada por meio da soma dos escores obtidos no teste. Cada questão previa pontuação máxima de 1 ponto. Nas questões discursivas, por tratar-se de avaliação subjetiva, seguindo o mesmo procedimento adotado nos protocolos verbais, a análise das respostas dos sujeitos foi realizada pelo pesquisador e por um avaliador, independentemente. Em caso de discrepância na nota do participante, um terceiro avaliador foi convidado a reanalisar as respostas e a participar de discussão com o pesquisador e o primeiro avaliador para buscar consenso.

Além dos quatro instrumentos de coleta centrais a esta pesquisa, aplicou-se, como instrumento complementar, uma bateria de três provas de raciocínio, padronizada para a população brasileira (PRIMI; ALMEIDA, 2000), com a intenção de controlar os resultados obtidos nos testes de capacidade de memória de trabalho e de alcançar informações mais amplas acerca do funcionamento cognitivo dos participantes. Destaca-se que a aplicação destas provas foi realizada com o objetivo de dar suporte aos testes de capacidade de memória, não sendo considerados seus resultados na discussão das perguntas e hipóteses de pesquisa. Esta bateria de provas de raciocínio ofereceu estimativas do funcionamento cognitivo geral e das habilidades do indivíduo em áreas específicas, conforme os testes selecionados: raciocínio abstrato, verbal e numérico.

$\mathrm{Na}$ condução das análises estatísticas, adotaram-se métodos não paramétricos (BISQUERRA; SARRIERA; MARTÍNEZ, 2004), aplicados por meio do pacote SPSS (Statistical Package for Social Science), a saber: 1) Coeficiente de Correlação de Spearman-Brown (rho - unidirecional), para medir a força e a significância da correlação entre as variáveis qualitativas ordinais: capacidade de memória de trabalho em leitura, capacidade de memória de trabalho em operações matemáticas, competência em leitura geral e competência em leitura das metáforas; 2) Prova de Mann-Whitney ( $U$ - bidirecional), para verificar a significância estatística da diferença entre médias de variáveis observadas sobre amostras independentes, isto é, variáveis observadas sobre dois grupos de estudantes com desempenhos diferentes; e 3) Prova T de Wilcoxon (bidirecional), aplicada na análise das diferenças entre os dados obtidos por meio dos protocolos verbais, de um mesmo participante, relativos ao texto 1 e ao texto 2 .

No que diz respeito ao estudo exploratório, que concerne ao agrupamento de participantes conforme o comportamento diante do texto e às relações entre as estratégias de leitura e a competência em leitura do texto geral e da metáfora, e entre estas mesmas estratégias e a capacidade de memória de trabalho, foram conduzidas análises multivariadas por meio de Análise Fatorial de Correspondências Múltiplas, Análise de Classificação (Cluster Analysis) e Análise de Partição, todas realizadas utilizando-se o pacote estatístico SPAD (Système Portable pour l'Analyse Données) (ESCOFIER; PAGÈS, 1992). Essa ferramenta foi adotada por causa da natureza qualitativa das variáveis e, também, porque toda a análise recaiu sobre o comportamento dos participantes, considerando simultaneamente todas as dimensões (estratégias).

Por fim, salienta-se que, em pesquisa de natureza psicolinguística que envolva participantes, materiais, coletas e análises de dados, como esta que aqui se apresentou, o rigor metodológico é essencial e implica um necessário e profundo conhecimento da literatura não somente naquilo que compete ao objeto, aos sujeitos e à situação de pesquisa, mas também, em igual medida, um conhecimento apurado dos fundamentos subjacentes ao método (natureza da investigação, instrumentos, instruções e procedimentos de coleta e análise de dados) com vistas ao alcance de objetivos e à busca de respostas às questões de pesquisa e testagem de hipóteses.

\section{A centralidade do método nas pesquisas psicolinguísticas}

Neste artigo, o objetivo central foi apresentar, fundamentar e discutir aspectos relativos aos instrumentos e procedimentos dos métodos de duas pesquisas de doutorado, desenvolvidas na área de Psicolinguística, no Programa de Linguística da UFSC. Ao apresentar as pesquisas de Heinig (2003) e de Souza (2004), as autoras aproveitaram para revisitar suas pesquisas com um olhar para os aspectos metodológicos, passados dez anos, tendo em vista que pesquisas atuais na mesma área nem sempre apresentam um desenho metodológico primoroso. Este retrospecto, feito a partir do presente, estando ambas em outra posição, a de orientar e analisar pesquisas, é uma atitude que se estende à área da Psicolinguística. A definição da metodologia requer do pesquisador uma gama de cuidados que, se não forem tomados, podem gerar problemas e inviabilidades tanto para a coleta dos dados como para a sua análise criteriosa. Diante disso, partindo do que foi apresentando nas seções anteriores, alguns aspectos precisam ser considerados.

A Psicolinguística é a ciência que investiga, entre outros, os processos de aprendizagem da leitura e da escrita, abarcando a decodificação e a codificação. Um dos ramos dessa ciência é a Psicolinguística Aplicada que "tem por escopo, como o nome indica, aplicar os achados da pesquisa fundamental em psicolinguística ao equacionamento de problemas em campos afins, como, por exemplo: a tradução, os distúrbios de comunicação, o 
ensino de primeiras e $n$ línguas, o ensino da lecto-escritura e a análise dos textos literários" (SCLIAR-CABRAL, 1991, p. 151). Dentre os campos citados, interessou, na tese de Heinig (2003), o do ensino da lecto-escritura. Segundo a autora, embora a Psicolinguística não tenha o poder de resolver os problemas do analfabetismo, pode contribuir para que o quadro referente ao insucesso escolar seja minimizado devido aos avanços teóricos dessa ciência. Um dos caminhos para tal é a formação dos profissionais da educação, que atuam desde a Educação Infantil, especialmente no pré-escolar, passando pelos que ensinam nos primeiros anos do Ensino Fundamental e chegando até o nível superior no que diz respeito ao ensino/aprendizagem e ao processamento da leitura e da escrita. Além disso, cabe aos psicolinguistas "efetuar uma crítica permanente ao material pedagógico, aos currículos e, se possível, colaborar na confecção dos mesmos" (op. cit., p. 152). Nesse cenário, ao aproximar o estudo do processo de codificação de palavras de mesma classe gramatical em contexto competitivo e a sua aprendizagem, fez-se necessário, na pesquisa de Heinig, trazer uma metodologia mista que aproximasse a pesquisa experimental e a ação com intervenção colaborativa.

A compreensão da área da Psicolinguística Aplicada, a definição do tipo de pesquisa e, por conseguinte, a seleção de instrumentos de coleta de dados, exigiu uma descrição metodológica que possibilitou uma interpretação quanti e qualitativa dos dados para que se pudesse efetuar uma análise crítica do currículo, dos materiais didáticos, da metodologia de ensino bem como a apresentação de propostas de metodologia e de materiais provenientes de base teórica sólida para a aplicação em sala de aula e análise de seu uso no ensino da escrita.

No que diz respeito à pesquisa de Souza (2004), também situada no campo dos estudos psicolinguísticos em ambiente de ensino e aprendizagem, o foco recaiu sobre processos que envolvem a modalidade escrita da língua, fundamentalmente aqueles implicados na atividade de leitura com o propósito de estudo e sua relação com a capacidade cognitiva de memória de trabalho. A pesquisa de Souza, incitada pelo baixo nível de competência em leitura de estudantes universitários que se encontram às vias de assumir a função docente, visou identificar, examinar, compreender e discutir o comportamento e o desempenho dos participantes-alvo diante do texto em relação às suas capacidades cognitivas individuais de memória de trabalho.

Vale destacar que, além dos aspectos frisados neste artigo, a proposição e o desenvolvimento de pesquisa na área de Psicolinguística requer atenção à seleção do local e das condições da pesquisa e dos sujeitos participantes, sobretudo quando se pretende uma análise comparativa entre grupos. O controle das variáveis é fundamental para que se possam alcançar os objetivos que a pesquisa propõe.

Para finalizar, destaca-se que, quando o assunto é leitura e escrita, há ainda uma considerável lacuna no contexto escolar brasileiro. As pesquisas aqui apresentadas foram conduzidas no âmbito educacional; por isso, acredita-se que os resultados obtidos se constituem em mais uma fonte de referência à elaboração de estratégias e materiais de ensino de leitura e escrita. Evidentemente, sabe-se que o baixo nível de letramento não é uma questão exclusivamente vinculada aos estudantes, professores, metodologias e métodos. Trata-se de um problema amplo, envolvido em questões histórico-culturais, situadas na base de um processo em que o sistema educacional se torna adorno que não precisa ser ostentado. Mesmo conhecendo muitos dos inúmeros fatores envolvidos na grande carência de competência em leitura e, consequentemente, em escrita, urge tomar medidas conscientes e criteriosas para possibilitar ao estudante aquilo que lhe é de direito: o efetivo acesso à modalidade escrita da língua.

\section{Referências}

AFFLERBACH, Peter; JOHNSTON, Peter. Research methodology: on the use of verbal reports in reading research. Journal of Reading Behavior, v. 16, n. 4, p. 307-322, 1984.

ANDRÉ, Marli Eliza D. A. de. Etnografia na prática escolar. Campinas, SP: Papirus, 2008.

BARBIER, Rene. Pesquisa-ação na instituição educativa. Tradução de Estela dos Santos. Rio de Janeiro: Jorge Zahar Editor, 2002.

BECHARA, Evanildo. Moderna gramática portuguesa. São Paulo: Nacional, 1969.

BECHARA, Evanildo. Moderna gramática portuguesa. 37. ed. rev. e ampl. Rio de Janeiro: Lucerna, 2003.

BISQUERRA, Rafael; SARRIERA, Jorge Castellá; MARTÍNEZ, Francesc. Introdução à estatística: enfoque informático com o pacote estatístico SPSS. Tradução de Fátima Murad. Porto Alegre: Artmed, 2004.

BRASIL. Ministério da Educação. Pisa 2000: relatório nacional. Brasília, 2001.

CANTOR, Judy; ENGLE, Randall. Working memory capacity as long-term memory activation: an individual diferences approach. Journal of Experimental Psychology: Learning, Memory and Cognition, v. 19, n. 5, p. 1101-1114, 1993. http:// dx.doi.org/10.1037/0278-7393.19.5.1101

CHIZZOTTI, Antonio. Pesquisa em ciências humanas e sociais. São Paulo: Cortez, 2008.

DANEMAN, Meredyth; CARPENTER, Patricia. Individual differences in working memory and reading. Journal of Verbal Learning \& Verbal Behavior, v. 19, p. 450-466, 1980. http:// dx.doi.org/10.1016/S0022-5371(80)90312-6

DANEMAN, Meredyth; MERIKLE, Phillip. M. Working memory and language comprehension: a meta-analysis. 
Psychonomic Bulletin \& Review, v. 3, n. 4, p. 422-433, 1996. http://dx.doi.org/10.3758/BF03214546

ERICSSON, Anders; SIMON, Herbert A. Verbal Reports as Data. Psychological Review, v. 87, n. 3, p. 215-251, 1980. http:// dx.doi.org/10.1037/0033-295X.87.3.215

ERICSSON, Anders; SIMON, Herbert A. Protocols analysis: verbal reports as data. Revised edition. Cambridge: MIT Press, 1993.

ERICSSON, Anders; SIMON, Herbert A. How to study thinking in everyday life: contrasting think-aloud protocols with descriptions and explanations of thinking. Mind, Culture and Activity, v. 5, n. 3, p. 178-186, 1998. http://dx.doi.org/10.1207/ s15327884mca0503_3

ESCOFIER, Brigitte; PAGÈS, Jérôme. Análisis fatoriales simples y múltiples: objetivos, metodos y interpretación. Bilbao: Servicio Editorial de la Universidad del País Basco, 1992.

FORTKAMP, Mailce Borges Mota. Working memory capacity and L2 speech production: an exploratory study. 2000. 230f. Tese (Doutorado em Letras opção Língua Inglesa e Linguística Aplicada) - Pós-Graduação em Inglês e Literatura Correspondente, Florianópolis.

HAGUETTE, Teresa M. F. Metodologias qualitativas na sociologia. Petrópolis: Vozes, 2003.

HEINIG, Otília Lizete de Oliveira Martins. "É que a gente não sabe o significado": homófonos não homógrafos. 2003. 251f. Tese (Doutorado em Linguística) - Pós-Graduação em Linguística, Florianópolis.

KIRSCH, Irwin. The International Adult Literacy Survey (IALS): Understanding what was measured. Princeton: Education Testing Service, 2001.

LISITA, Verbena; ROSA, Dalva; LIPOVETSKY, Noêmia. Formação de professores e pesquisa: uma relação possível. In: ANDRÉ, Marli Eliza D. A. de (Org.). O papel da pesquisa na formação e na prática dos professores. 2. ed. Campinas, SP: Papirus, 2002. p. 107-127.

MESQUITA, Roberto M. Gramática da língua portuguesa. São Paulo: Saraiva, 1994.

ORGANISATION FOR ECONOMIC CO-OPERATION AND DEVELOPMENT. The Pisa 2003 Assessment Framework: mathematics, reading, science and problem solving knowledge and skills. Paris: OECD Publications, 2003.

PRIMI, Ricardo; ALMEIDA, Leandro. BPR-5: Bateria de provas de raciocínio: manual técnico. São Paulo: Casa do Psicólogo, 2000.
ROCHA LIMA. Gramática normativa da língua portuguesa. 22. ed. Rio de Janeiro: José Olympio, 1982.

SACCONI, Luiz Antonio. Nossa gramática: teoria e prática. 18. ed. São Paulo: Atual, 1994.

SANTOS, Lucíola L. C. P. Dilemas e perspectivas na relação entre ensino e pesquisa. In: ANDRÉ, Marli Eliza D. A. de (Org.). O papel da pesquisa na formação e na prática dos professores. 2. ed. Campinas, SP: Papirus, 2002. p. 11-25.

SCLIAR-CABRAL, Leonor. Guia prático de alfabetização, baseado em princípios do sistema alfabético do português do Brasil. São Paulo: Contexto, 2003.

SCLIAR-CABRAL, Leonor. Introdução à psicolinguística. São Paulo: Ática, 1991.

SOUZA, Ana Cláudia. Leitura, metáfora e memória de trabalho: três eixos imbricados. 2004. 231f. Tese (Doutorado em Linguística) - Pós-Graduação em Linguística, Florianópolis.

SOUZA, Ana Cláudia de; RODRIGUES, Cassio. Protocolos verbais: uma metodologia na investigação de processos de leitura. In: TOMITCH, Lêda Maria Braga (Org.). Aspectos cognitivos e instrucionais da leitura. Bauru, SP: EDUSC, 2008. p. 19-36.

THIOLLENT, Michel. Pesquisa-ação nas organizações. São Paulo: Atlas, 2009.

TOMITCH, Lêda Maria Braga. Reading: text organization perception and working memory capacity. Florianópolis: UFSC, Departamento de Língua e Literatura Estrangeiras, 2003.

TORRES, Ana Cecília Gama. Working memory capacity and reader's performance on main idea construction in L1 and L2. 2003. 295f. Tese (Doutorado em Letras/Inglês e Literatura Correspondente) - Florianópolis.

TURNER, Marilyn; ENGLE, Randall. Is working memory capacity task dependent? Journal of memory and language, v. 28 , p. $127-154,1989$. http://dx.doi.org/10.1016/0749-596X (89)90040-5

VAN BESIEN, Fred. Metaphors in scientific language. Communication and Cognition, v. 22, n. 1, p. 5-22, 1989.

Recebido: 31 de agosto de 2014

Aprovado: 28 de outubro de 2014

Contatos:anacs3@gmail.com otilia.heinig@gmail.com 